\title{
Geriatric hospitalizations in fall-related injuries
}

\author{
Cheng-Shyuan Rau ${ }^{1 \dagger}$, Tsan-Shiun Lin ${ }^{2 \dagger}$, Shao-Chun Wu ${ }^{3}$, Johnson Chia-Shen Yang ${ }^{4}$, Shiun-Yuan Hsu², \\ Tzu-Yu Cho ${ }^{2}$ and Ching-Hua Hsieh ${ }^{2 *}$
}

\begin{abstract}
Background: To investigate the injury pattern, severity, and mortality of elderly patients hospitalized for treatment of trauma following fall accidents.

Methods: Data obtained from the Trauma Registry System were retrospectively reviewed for trauma admissions between January 1, 2009 and December 31, 2013 in a Level I trauma center. Of 16,548 registered patients, detailed information was retrieved from the 2,403 elderly patients (aged 65 years and above) with fall accidents and was compared with information from 1,909 adult patients (aged 20-64) with fall accidents.

Results: Falls presented the major mechanism for admission (59.9\%) in the elderly patients. The number of elderly patients who fell from a height $<1 \mathrm{~m}$ was greater than that of the adult patients (91.9\% vs. 62.5\%, respectively, $p<0.001)$. The Injury Severity Score (ISS) $(9.3 \pm 4.4$ vs. $8.3 \pm 6.1$, respectively, $p=0.007)$ and New Injury Severity Score (NISS) (10.3 \pm 6.8 vs. $9.5 \pm 8.2$, respectively, $\mathrm{p}<0.001)$ were significantly higher in the elderly than the adult patients. A significantly larger proportion of the elderly patients were admitted to the ICU $(16.2 \% \mathrm{vs}$. $13.4 \%$, respectively, $p=0.009$ ), and the elderly were found to have longer stays in the intensive care unit (ICU) (8.6 days vs. 7.6 days, respectively, $p=0.034$ ) but not in the hospital in general (9.6 days vs. 8.5 days, respectively, $p=0.183$ ). Additionally, a significantly higher percentage of the elderly patients sustained subdural hematoma ( $10.1 \% \mathrm{vs} .8 .2 \%$, respectively, $p=0.032)$ and femoral fracture $(50.6 \%$ vs. $14.1 \%$, respectively, $p<0.001)$. There were significant differences in in-hospital mortality (18.2\% vs. $10.3 \%$, respectively, $p=0.031)$ and length of stay in the hospital (11.6 days vs. 14.9 days, respectively, $p=0.037$ ) between the elderly and adult patients with subdural hematoma, but not between those with femoral fracture.
\end{abstract}

Conclusions: Analysis of the data indicates that elderly patients hospitalized for treatment of trauma following fall accidents present with a bodily injury pattern that differs from that of adult patients and have a higher severe injury score, worse outcome, and higher mortality than those of adult patients.

Keywords: Elderly, Injury Severity Score (ISS), Mortality, Fall

\section{Background}

Falls are a leading cause of injury and death among the elderly and a significant public health issue [1-3]. Approximately one-third of the population over the age of 65 experiences falls each year, a figure that rises to over $50 \%$ among individuals aged 80 and above $[4,5]$. In addition, the incidence of falls that lead to admission to emergency units is increasing with the increased size and rapid growth of the geriatric population [6,7]. The rates of

\footnotetext{
*Correspondence: m93chinghua@gmail.com

${ }^{\dagger}$ Equal contributors

${ }^{2}$ Department of Trauma Surgery, Kaohsiung Chang Gung Memorial Hospital and Chang Gung University College of Medicine, No.123, Ta-Pei Road,

Niao-Song District, Kaohsiung City 833, Taiwan

Full list of author information is available at the end of the article
}

fall-induced deaths and the absolute number of these deaths, are increasing rapidly $[8,9]$. Therefore, considering the fact that approximately $25 \%$ of the population of Western countries will be in the geriatric age group by the year 2030, hospitalization of geriatric patients for fallrelated injuries will become a major issue in the future [10]. Moreover, the acute medical care costs of fall-related injuries will continue to rise in the growing population of the elderly who are living longer and engaging in activities at higher risk of injury [11].

There is strong evidence that elderly trauma patients are at an increased risk of morbidity and mortality compared to younger patients [12-14]. In addition, elderly patients sustain distinct patterns of injuries from causes 
that differ from those of non-elderly adults because of their unique anatomical, physiologic, and behavioral characteristics. The effect of trauma would decrease both the ability to live an active lifestyle and the physiologic capacity in elderly patients [15]. Geographic variation in trauma patterns may occur, but there is limited information available about falls among the geriatric population in Taiwan. The purpose of this epidemiologic study was to assess the clinical characteristics and outcomes of elderly patients admitted for treatment for fall-related injuries in a Level I trauma center over a five-year period using data from a population-based trauma registry.

\section{Methods}

\section{Study design}

The study was conducted at Kaohsiung Chang Gung Memorial Hospital, a 2,400-bed facility and a Level I regional trauma center that provides care to trauma patients primarily from South Taiwan. Approval for this study was obtained from the hospital's institutional review board (approval number 103-3035B) before its initiation. This retrospective study was designed to review all the data added to the Trauma Registry System from January 1, 2009 to December 31, 2013 for cases that visited our emergency room with any trauma mechanism and met the inclusion criteria of (1) age $\geq 65$ years and (2) hospitalization for treatment of trauma sustained in a fall. For comparison, data regarding adults aged 20 to 64 years old were also collected.

Among the 16,548 hospitalized registered patients entered in the database, 4,011 (24.2\%) were $\geq 65$ years of age (hereafter referred to as the elderly) and 10,234 $(61.8 \%)$ were 20 to 64 years of age (hereafter referred to as adults). Cut-off age of 20 was arbitrarily selected to be an adult because there is a legal requirement of supervisor to proceed health care such as admission, invasive procedure, and operation in Taiwan until the patient turns 20 years old. Among these patients, 2,403 (59.9\%) elderly and 1,909 (18.7\%) adults had been admitted due to a fall accident. Detailed patient information was retrieved from the Trauma Registry System of our institution and included data regarding age, sex, height of fall, and vital signs on arrival, as well as the first Glasgow Coma Scale (GCS) score in the emergency department, Abbreviated Injury Scale (AIS) scores for each body region, Injury Severity Score (ISS), New Injury Severity Score (NISS), Trauma and Injury Severity Score (TRISS), length of hospital stay (LOS), length of intensive care unit stay (LICUS), in-hospital mortality, and associated complications. AIS scores every injury and classified each according to six severity as (1) minor, (2) mild, (3) serious, (4) severe, (5) critical, and (6) mortal [16]. The ISS is the sum of the square of the three most severe injuries, but it only considers one injury per body region [17]. The NISS, a modification of the ISS in 1997, is defined as the sum of a patient's three most severe injuries, regardless of body region [18]. The TRISS utilizes the patient's age, type of injury, Revised Trauma Score (RTS), and the ISS to estimate the probability of survival [19]. Among the TRISS, the RTS is calculated using the GCS score, the systolic blood pressure (SBP), and respiratory rate (RR) [20]. In brief, AIS, ISS, and NISS are anatomical, GCS and RTS are physiological scoring systems and TRISS is a combined scoring system for survival prediction. In this study, the primary outcome is the injury severity by different scoring system (GCS, AIS, ISS, NISS, TRISS) and the secondary outcome is LOS, LICUS, and in-hospital mortality. In addition, the pre-existed comorbidities and chronic diesases including diabetes mellitus (DM), hypertension (HTN), coronary artery diseases (CAD), congestive heart failure (CHF), cerebrovascular accident (CVA), and end-stage renal disease (ESRD) were identified. Adjusted odd ratios (AOR) of the mortality according to these pre-existed comorbidities, chronic diesases and ISS with 95\% confidence intervals (CI) of this AOR calculated. The data collected regarding the populations of elderly and adults were compared using SPSS v.20 statistical software (IBM Corporation, Armonk, NY, USA) for performance of Pearson's chi-squared test, Fisher's exact test, or the independent Student's $t$ test, as applicable. All results are presented as the mean \pm standard error. A p-value less than 0.05 was considered statistically significant.

\section{Results}

\section{Patient characteristics}

As shown in Figure 1, fall presented the major mechanism for admission (59.9\%) in the elderly patients, followed by motorcycle accident (24.8\%). In contrast, motorcycle accident presented the major mechanism for admission $(49.6 \%)$ in the adult patients, followed by unspecific mechanisms, which included fight, suicide, and unknown and unclassified injuries. Fall presented the mechanism for admission in $18.7 \%$ of the injured adult patients.

Of the 2,403 elderly and 1,909 adult patients injured in a fall, the mean ages were $78.0 \pm 7.3$ and $49.8 \pm 11.1$ years, respectively (Table 1 ). A statistically significant difference regarding sex was found between the elderly. In the group of elderly patients, more than two times as many women as men were injured in a fall; however, among the adult patients, more men were injured in a fall. There were significant higher incidence rates of the pre-existed comorbidities and chronic diesases including DM, HTN, CAD, CHF, CVA, and ESRD in the elderly patients. Analysis of the data regarding height of fall $(<1 \mathrm{~m}, 1-6 \mathrm{~m},>6 \mathrm{~m})$ revealed that the majority of both the elderly and adult patients fell from a height $<1 \mathrm{~m}$, but more adult than elderly 


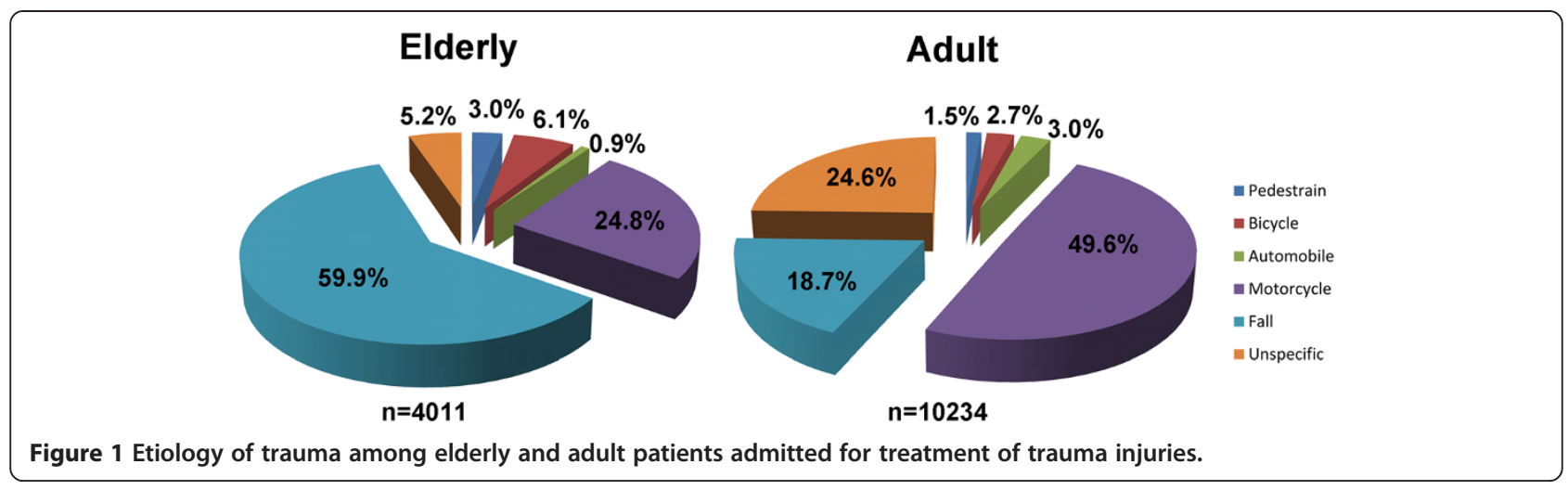

patients fell from a height between 1-6 $\mathrm{m}$ and $>6 \mathrm{~m}$, implying that the majority of the elderly patients sustained a ground-level fall occurring upon walking or with movement and that more adult than elderly patients sustained a non-ground-level fall occurring with more rigorous activity. No significant difference was found between the elderly and adult patients regarding GCS score or distribution of patients at different levels of consciousness (GCS $\leq 8,9-12$, or $\geq 13$ ). Analysis of AIS scores revealed that the elderly patients sustained significantly higher rates of extremity injury than the adult patients, while the adult patients sustained significantly higher rates of injuries to face, thorax, and abdomen. On the other hand, no significant differences regarding injury to the head/neck region were found between the elderly and adult patients.

Comparison of trauma injury scores for the elderly and adult patients indicated significant differences regarding ISS ( $9.3 \pm 4.4$ vs. $8.3 \pm 6.1$, respectively, $\mathrm{p}<0.001)$. The ISS was higher in the elderly than that in the adult patients; however, when stratified into different groups of injury severity $(<16,16-24, \geq 25)$, the ISS of the elderly was higher than that of the adult patients only in the group of ISS $<16$. In the groups of ISS between 16-24 and $\geq 25$, the ISS of the adult patients was significantly higher than that of the elderly. Likewise, there were also significant differences regarding NISS and in-hospital mortality, but not TRISS between these two groups of patients. The mortality rate was higher among men than women in both the elderly and the adult patients. However, there was no significant different AOR of the mortality for the elderly after the adjustment according to the pre-existing comorbidities, chronic diseases, and ISS (AOR $=0.40,95 \%$ CI: 0.13-1.20), indicating the pre-existing comorbidities and chronic disease may be responsible for the higher incidence rates of mortality in the elderly. No significant differences were found between the elderly and adult patients regarding hospital LOS. However, a significantly larger proportion of the elderly patients were admitted to the ICU, with longer LICUS. Among patients with ISS $<16,8.3 \%$ of the elderly and $5.2 \%$ of the adult patients were admitted to the ICU ( $\mathrm{p}<0.001$ ), with longer LICUS. In addition, $66.8 \%$ of the elderly and $59.0 \%$ of the adult patients with ISS $16-24$, and $91.2 \%$ of the elderly and $80.9 \%$ of the adult patients with ISS $\geq 25$ were admitted to the ICU. No significant differences regarding the proportion of patients admitted to the ICU and LICUS were found between the elderly and adult patients with ISS $16-24$ and ISS $\geq 25$. However, among patients admitted to ICU and with ISS $\geq 25$, the elderly experienced longer stays in the ICU than the adult patients.

Table 2 shows the findings regarding injury associated with the fall accidents. As observed, a significantly higher percentage of elderly than adult patients sustained subdural hematoma and femoral fracture, but the elderly experienced a significantly lower percentage of other injuries. Furthermore, subsequent analysis focused on subdural hematoma (Table 3) and femoral fracture (Table 4), the associated injuries, which were significantly higher among the elderly with fall accidents. In the patients with subdural hematoma following a fall (elderly $n=242$, adults $\mathrm{n}=156$ ), the analysis revealed significant differences in sex between the elderly. No significant difference was found between the elderly and adult patients with subdural hematoma regarding GCS score. The ISS was higher in the adult patients than that in the elderly (18.8 \pm 7.8 vs. $17.1 \pm 5.7$, respectively, $\mathrm{p}<0.001)$. In addition, there were significant differences between the elderly and the adult patients with subdural hematoma regarding in-hospital mortality and length of stay in the hospital. Even after the adjustment according to the pre-existing comorbidities, chronic diseases, and ISS, there was still a greater odds of mortatlity for the elderly (AOR $=1.9,95 \% \mathrm{CI}$ : 1.06-3.59). However, the mortality rate among men and women with subdural hematoma was not significantly different in either the elderly or the adult patients. No significant differences were found between the elderly and adult patients with subdural hematoma regarding NISS, TRISS, proportion of patients admitted to the ICU and receiving operations, and the number of operations. However, among the 
Table 1 Demographics of hospitalized elderly and adult trauma patients in fall accidents

\begin{tabular}{|c|c|c|c|c|c|}
\hline \multirow{3}{*}{$\begin{array}{l}\text { Variable } \\
\text { Age }\end{array}$} & \multirow{2}{*}{\multicolumn{2}{|c|}{$\begin{array}{l}\text { Elderly } \\
\mathrm{N}=2403\end{array}$}} & \multirow{2}{*}{\multicolumn{2}{|c|}{$\begin{array}{l}\text { Adult } \\
\mathrm{N}=1909\end{array}$}} & \multirow[t]{3}{*}{$p$} \\
\hline & & & & & \\
\hline & 78.0 & \pm 7.3 & 49.8 & \pm 11.1 & \\
\hline \multicolumn{5}{|l|}{ Gender, n (\%) } & \multirow[t]{3}{*}{$<0.001$} \\
\hline Male & 788 & (32.8) & 1171 & (61.3) & \\
\hline Female & 161 & $(67.2)$ & 73 & (38.7) & \\
\hline \multicolumn{6}{|l|}{ Co-morbidity } \\
\hline DM & 740 & (30.8) & 295 & $(15.5)$ & $<0.001$ \\
\hline HTN & 1493 & (62.1) & 451 & (23.6) & $<0.001$ \\
\hline CAD & 221 & $(9.2)$ & 48 & $(2.5)$ & $<0.001$ \\
\hline $\mathrm{CHF}$ & 71 & (3.0) & 16 & $(0.8)$ & $<0.001$ \\
\hline CVA & 335 & $(13.9)$ & 168 & (3.6) & $<0.001$ \\
\hline ESRD & 123 & $(5.1)$ & 64 & (3.4) & 0.005 \\
\hline \multicolumn{6}{|c|}{ Fall height, n (\%) } \\
\hline$<1 \mathrm{~m}$ & 2209 & (91.9) & 1194 & (62.5) & $<0.001$ \\
\hline $1-6 m$ & 191 & $(7.9)$ & 672 & $(35.2)$ & $<0.001$ \\
\hline$>6 \mathrm{~m}$ & 3 & $(0.1)$ & 43 & $(2.3)$ & $<0.001$ \\
\hline GCS & 14.5 & \pm 1.9 & 14.4 & \pm 2.0 & 0.283 \\
\hline$\leq 8$ & 69 & (2.9) & 74 & (3.9) & 0.067 \\
\hline $9-12$ & 92 & (3.8) & 57 & (3.0) & 0.132 \\
\hline$\geq 13$ & 2242 & (93.3) & 1778 & $(93.1)$ & 0.833 \\
\hline
\end{tabular}

AIS, n (\%)

$\begin{array}{llllll}\text { Head/Neck } & 510 & (21.2) & 451 & (23.6) & 0.060 \\ \text { Face } & 99 & (4.1) & 161 & (8.4) & <0.001 \\ \text { Thorax } & 129 & (5.4) & 209 & (10.9) & <0.001 \\ \text { Abdomen } & 102 & (4.2) & 149 & (7.8) & <0.001 \\ \text { Extremity } & 1857 & (77.3) & 1408 & (73.8) & 0.007 \\ \text { ISS, n (\%) } & & & & & \\ <16 & 2106 & (87.6) & 1646 & (86.2) & 0.169 \\ \text { 16-24 } & 229 & (9.5) & 195 & (10.2) & 0.453 \\ \geq 25 & 68 & (2.8) & 68 & (3.6) & 0.172 \\ \text { ISS } & 9.3 & \pm 4.4 & 8.3 & \pm 6.1 & <0.001 \\ <16 & 8.0 & \pm 2.4 & 6.4 & \pm 2.9 & <0.001 \\ \text { 16-24 } & 16.7 & \pm 1.4 & 17.3 & \pm 2.1 & <0.001 \\ \geq 25 & 25.8 & \pm 2.2 & 29.4 & \pm 8.0 & <0.001 \\ \text { NISS } & 10.3 & \pm 6.8 & 9.5 & \pm 8.2 & <0.001 \\ \text { TRISS } & 0.99 & \pm 0.12 & 0.99 & \pm 0.12 & 0.768 \\ \text { Mortality, n (\%) } & 78 & (3.2) & 25 & (1.3) & <0.001 \\ \text { Men } & 46 & (5.8) & 22 & (1.9) & \\ \text { Female } & 32 & (2.0) & 3 & (0.4) & \\ \text { AOR (95\%Cl) } & 0.40 & (0.13-1.20) & & & 0.103 \\ \text { LOS (days) } & 9.6 & \pm 8.7 & 8.5 & \pm 9.4 & 0.183\end{array}$

ICU
Table 1 Demographics of hospitalized elderly and adult trauma patients in fall accidents (Continued)

\begin{tabular}{clllll}
\hline Patients, n (\%) & 390 & $(16.2)$ & 225 & $(13.4)$ & 0.009 \\
$<16$ & 175 & $(8.3)$ & 85 & $(5.2)$ & $<0.001$ \\
$16-24$ & 153 & $(66.8)$ & 115 & $(59.0)$ & 0.095 \\
$\geq 25$ & 62 & $(91.2)$ & 55 & $(80.9)$ & 0.083 \\
LICUS (days) & 8.6 & \pm 11.4 & 7.6 & \pm 9.1 & 0.034 \\
$<16$ & 6.8 & \pm 8.3 & 5.1 & \pm 5.8 & 0.032 \\
$16-24$ & 8.8 & \pm 12.3 & 7.4 & \pm 10.0 & 0.092 \\
$\geq 25$ & 13.3 & \pm 14.7 & 12.0 & \pm 9.6 & 0.018 \\
\hline
\end{tabular}

patients with ISS $<16$, the elderly had a significantly longer length of stay in the hospital than the adult patients.

In the patients with femoral fracture following a fall (elderly $\mathrm{n}=1,215$, adults $\mathrm{n}=270$ ), significant differences regarding sex were found between the elderly. The adult patients had significantly higher ISS $(9.7 \pm 3.2$ vs. $9.2 \pm 1.5$, respectively, $\mathrm{p}<0.001)$, NISS, and TRISS than the elderly. However, there were no significant differences between the elderly and the adult patients with femoral fracture regarding in-hospital mortality, adjusted odds of mortality (AOR $=3.1,95 \%$ CI: 0.41-23.95) and length of stay in the hospital. The mortality rate among men and women with femoral fracture was also not significantly different in either the elderly or the adult patients. There was a significantly higher proportion of patients admitted to the ICU among the group of elderly patients with ISS $<16$ when compared to the adult patients in the same group of injury severity; however, the length of stay in the ICU did not differ between these two groups of patients with femoral fracture. In contrast, elderly patients with ISS $\geq 25$ experienced longer stays in the ICU than adult patients with ISS $\geq 25$. The proportion of adult patients receiving operations was significantly higher than that of the elderly, but the number of operations performed did not differ. Regarding the location of the femur fracture, the elderly sustained more intertrochanteric fracture but less femoral shaft fracture and femoral head fracture than the adult patients.

\section{Discussion}

This study analyzed the demographics and characteristics of injuries observed in a geriatric population presenting at a Level I trauma center following fall accidents. Analysis of the data indicates that elderly patients present with a bodily injury pattern that differs from that of adult patients, and have a higher injury severity, worse outcome, and higher mortality than those of adult patients.

Notably, in this study, the elderly patients had a mean age of close to 80, much higher than the cutoff of 65 used in the general part of this study, and represent a even higher risk group. As shown, more than two times 
Table 2 Associated injuries of hospitalized elderly and adult patients in fall accidents

\begin{tabular}{llll}
\hline Fall accident & & & \\
\hline Variable & Elderly & Adult & $p$ \\
& $\mathrm{~N}=2403$ & $\mathrm{~N}=1909$ & \\
\hline
\end{tabular}

Head trauma, $\mathrm{n}(\%)$

Neurologic deficit+

Cranial fracture+

Epidural hematoma $(E D H)+$

Subdural hematoma $(\mathrm{SDH})^{*}$

Subarachnoid hemorrhage (SAH)

Intracerebral hematoma $(\mathrm{ICH})$

Cerebral contusion

$N=2403 \quad N=1909$

Cervical vertebral fracture+

Maxillofacial trauma, n (\%)

\begin{tabular}{|c|c|c|c|c|c|}
\hline Maxillary fracture+ & 20 & $(0.8)$ & 47 & $(2.5)$ & $<0.001$ \\
\hline Mandibular fracture+ & 2 & $(0.1)$ & 20 & $(1.0)$ & $<0.001$ \\
\hline Orbital fracture+ & 5 & $(0.2)$ & 12 & $(0.6)$ & 0.029 \\
\hline Nasal fracture & 6 & $(0.2)$ & 10 & $(0.5)$ & 0.141 \\
\hline \multicolumn{6}{|l|}{ Thoracic trauma, n (\%) } \\
\hline Rib fracture+ & 77 & $(3.2)$ & 142 & $(7.4)$ & $<0.001$ \\
\hline Sternal fracture+ & 0 & $(0.0)$ & 5 & $(0.3)$ & 0.012 \\
\hline Hemothorax+ & 14 & $(0.6)$ & 25 & $(1.3)$ & 0.012 \\
\hline Pneumothorax+ & 5 & $(0.2)$ & 31 & $(1.6)$ & $<0.001$ \\
\hline Lung contusion+ & 2 & $(0.1)$ & 12 & $(0.6)$ & 0.002 \\
\hline Hemopneumothorax+ & 5 & $(0.2)$ & 31 & $(1.6)$ & $<0.001$ \\
\hline Thoracic vertebral fracture+ & 37 & $(1.5)$ & 57 & $(3.0)$ & 0.001 \\
\hline \multicolumn{6}{|l|}{ Abdominal trauma, n (\%) } \\
\hline Intra-abdominal injury+ & 3 & $(0.1)$ & 20 & $(1.0)$ & $<0.001$ \\
\hline Hepatic injury+ & 3 & $(0.1)$ & 18 & $(0.9)$ & $<0.001$ \\
\hline Splenic injury & 1 & $(0.04)$ & 5 & $(0.3)$ & 0.054 \\
\hline Retroperitoneal injury & 2 & $(0.1)$ & 4 & $(0.2)$ & 0.269 \\
\hline Renal injury & 3 & $(0.1)$ & 7 & $(0.4)$ & 0.101 \\
\hline Urinary bladder injury & 1 & $(0.04)$ & 4 & $(0.2)$ & 0.108 \\
\hline Lumbar vertebral fracture+ & 64 & $(2.7)$ & 112 & $(5.9)$ & $<0.001$ \\
\hline Sacral vertebral fracture+ & 4 & $(0.2)$ & 22 & $(1.2)$ & $<0.001$ \\
\hline \multicolumn{6}{|l|}{ Extremity trauma, n (\%) } \\
\hline Scapular fracture & 6 & $(0.2)$ & 10 & $(0.5)$ & 0.141 \\
\hline Clavicle fracture+ & 25 & $(1.0)$ & 43 & $(2.3)$ & 0.002 \\
\hline Humeral fracture & 118 & $(4.9)$ & 101 & $(5.3)$ & 0.572 \\
\hline Radial fracture+ & 224 & $(9.3)$ & 363 & $(19.0)$ & $<0.001$ \\
\hline Ulnar fracture+ & 100 & $(4.2)$ & 119 & $(6.2)$ & 0.002 \\
\hline Femoral fracture* & 1215 & $(50.6)$ & 270 & $(14.1)$ & $<0.001$ \\
\hline Patella fracture+ & 55 & $(2.3)$ & 100 & $(5.2)$ & $<0.001$ \\
\hline Tibia fracture+ & 44 & $(1.8)$ & 111 & (5.8) & $<0.001$ \\
\hline Fibular fracture+ & 26 & $(1.1)$ & 67 & (3.5) & $<0.001$ \\
\hline
\end{tabular}

Table 2 Associated injuries of hospitalized elderly and adult patients in fall accidents (Continued)

\begin{tabular}{llllll}
\hline Metacarpal fracture+ & 7 & $(0.3)$ & 35 & $(1.8)$ & $<0.001$ \\
Metatarsal fracture+ & 12 & $(0.5)$ & 135 & $(7.1)$ & $<0.001$ \\
Calcaneal fracture+ & 57 & $(2.4)$ & 135 & $(7.1)$ & $<0.001$ \\
Pelvic fracture+ & 25 & $(1.0)$ & 58 & $(3.0)$ & $<0.001$ \\
\hline
\end{tabular}

+ and * indicated significant lower and higher incidences of the associated injury, respectively, in the elderly than those adult patients $(p<0.05)$. DM: diabetes mellitus; HTN: hypertension; CAD: coronary artery diseases; CHF: congestive heart failure; CVA: cerebrovascular accident; ESRD: end-stage renal disease.

as many elderly women as men were injured in a fall; however, greater mortality was noted among the elderly men than among the elderly women. In contrast, among the adult patients, more men were injured, and the men sustained a higher fatality rate in the fall accidents than

Table 3 Injury characteristics of hospitalized elderly and adult patients with subdural hematoma in fall accidents

Subdural hematoma

\begin{tabular}{|c|c|c|c|}
\hline \multirow[t]{2}{*}{ Variables } & Elderly & Adult & \multirow[t]{2}{*}{$p$} \\
\hline & $N=242$ & $N=156$ & \\
\hline Age & 77.7 & 49.4 & \\
\hline
\end{tabular}

Gender, n (\%)

$<0.001$

$\begin{array}{lllll}\text { Male } & 130 & (53.7) & 125\end{array}$

Female $\quad 112 \quad(46.3) \quad 31 \quad$ (19.9)

$\begin{array}{llllll}\text { GCS } & 12.3 & \pm 3.9 & 11.9 & \pm 4.3 & 0.341\end{array}$

$\begin{array}{llllll}\text { ISS } & 17.1 & \pm 5.7 & 18.8 & \pm 7.8 & <0.001\end{array}$

$\begin{array}{llllll}\text { NISS } & 21.6 & \pm 12.4 & 24.0 & \pm 14.6 & 0.274\end{array}$

$\begin{array}{llllll}\text { TRISS } & 0.849 & \pm 0.192 & 0.885 & \pm 0.181 & 0.261\end{array}$

$\begin{array}{llllll}\text { Mortality, } \mathrm{n}(\%) & 44 & (18.2) & 16 & \text { (10.3) } & 0.031\end{array}$

$\begin{array}{lllll}\text { Male } & 27 & (20.8) & 13 & (10.4)\end{array}$

$\begin{array}{lllll}\text { Female } & 17 & (15.2) & 3 & \text { (9.7) }\end{array}$

AOR $(95 \% \mathrm{Cl}) \quad 1.9 \quad(1.06-3.59) \quad 0.033$

$\begin{array}{llllll}\text { LOS (days) } & 11.6 & \pm 11.6 & 14.9 & \pm 14.0 & 0.037\end{array}$

ICU

$\begin{array}{llllll}\text { Patients, n (\%) } & 173 & (71.5) & 106 & (67.9) & 0.452 \\ <16 & 20 & (48.8) & 13 & (54.2) & 0.675 \\ 16-24 & 107 & (71.3) & 59 & (65.6) & 0.348 \\ \geq 25 & 46 & (90.2) & 34 & (81.0) & 0.201 \\ \text { LICUS (days) } & 8.5 & \pm 10.7 & 7.8 & \pm 8.5 & 0.158 \\ <16 & 5.6 & \pm 6.1 & 3.0 & \pm 0.8 & 0.014 \\ 16-24 & 7.9 & \pm 10 . & 6.6 & \pm 8.2 & 0.130 \\ \geq 25 & 11.1 & \pm 13.1 & 11.7 & \pm 9.2 & 0.119 \\ \text { Operation, n (\%) } & & & & & 0.102\end{array}$

\begin{tabular}{llllll} 
Yes & 58 & $(24.0)$ & 49 & $(31.4)$ & \\
No & 184 & $(76.0)$ & 107 & $(68.6)$ & \\
Operation & 1.4 & \pm 0.7 & 1.6 & \pm 1.0 & 0.063 \\
\hline
\end{tabular}


Table 4 Injury characteristics of hospitalized elderly and adult patients with femoral fracture in fall accidents

\begin{tabular}{|c|c|c|c|c|c|}
\hline \multicolumn{6}{|l|}{ Femoral fracture } \\
\hline \multirow[t]{2}{*}{ Variables } & \multicolumn{2}{|c|}{ Elderly } & \multicolumn{2}{|l|}{ Adult } & \multirow[t]{2}{*}{$p$} \\
\hline & \multicolumn{2}{|c|}{$\mathrm{N}=1215$} & \multicolumn{2}{|c|}{$\mathrm{N}=\mathbf{2 7 0}$} & \\
\hline Age & 79.5 & \pm 7.0 & 53.8 & \pm 9.5 & \\
\hline Gender, n (\%) & & & & & $<0.001$ \\
\hline Male & 336 & $(27.7)$ & 147 & $(54.4)$ & \\
\hline Female & 879 & $(72.3)$ & 123 & $(45.6)$ & \\
\hline ISS & 9.2 & \pm 1.5 & 9.7 & \pm 3.2 & $<0.001$ \\
\hline NISS & 9.6 & \pm 2.1 & 10.1 & \pm 3.7 & $<0.001$ \\
\hline TRISS & 0.965 & \pm 0.013 & 0.975 & \pm 0.019 & $<0.001$ \\
\hline Mortality, n (\%) & 14 & $(1.2)$ & 1 & $(0.4)$ & 0.245 \\
\hline Male & 5 & $(1.5)$ & 1 & $(0.7)$ & \\
\hline Female & 9 & $(1.0)$ & 0 & $(0.0)$ & \\
\hline AOR $(95 \% \mathrm{Cl})$ & 3.1 & $(0.41-23.95)$ & & & 0.271 \\
\hline LOS (days) & 9.8 & \pm 7.1 & 8.5 & \pm 7.3 & 0.846 \\
\hline \multicolumn{6}{|l|}{ ICU } \\
\hline Patients, n (\%) & 84 & $(6.9)$ & 12 & $(4.4)$ & 0.136 \\
\hline$<16$ & 78 & $(6.5)$ & 7 & $(2.7)$ & 0.017 \\
\hline $16-24$ & 4 & $(44.4)$ & 1 & $(20.0)$ & 0.360 \\
\hline$\geq 25$ & 2 & $(40.0)$ & 4 & $(100.0)$ & 0.058 \\
\hline \multicolumn{6}{|l|}{ LICUS (days) } \\
\hline$<16$ & 6.2 & \pm 9.2 & 7.9 & \pm 4.3 & 0.733 \\
\hline $16-24$ & 12.5 & \pm 12.8 & 4 & & - \\
\hline$\geq 25$ & 16.5 & \pm 13.4 & 6.5 & \pm 3.7 & 0.003 \\
\hline Operation, n (\%) & & & & & $<0.001$ \\
\hline Yes & 438 & $(36.0)$ & 142 & $(52.6)$ & \\
\hline No & 777 & $(64.0)$ & 128 & $(47.4)$ & \\
\hline Operation & 1.0 & \pm 0.8 & 1.0 & \pm 0.8 & 0.962 \\
\hline \multicolumn{6}{|l|}{ Diagnosis } \\
\hline Femoral head & 43 & (3.5) & 24 & $(8.9)$ & $<0.001$ \\
\hline Femoral neck & 533 & $(43.9)$ & 112 & $(41.5)$ & 0.474 \\
\hline Intertrochanteric & 586 & $(48.2)$ & 89 & (33.0) & $<0.001$ \\
\hline Femoral shaft & 70 & $(5.8)$ & 53 & (19.6) & $<0.001$ \\
\hline
\end{tabular}

that of the women. These results are in agreement with those of studies showing that falls are more common in older women than men, that elderly women account for the majority of fall-related emergency department visits $[2,21,22]$, and that the death rate associated with falls is $46 \%$ higher for men than for women [23]. Although some studies have found that men comprised a significantly greater proportion of fall victims $[24,25]$, and the exact reasons for the disparity between men and women in fall-induced deaths are still largely unknown [26], elderly men might engage in riskier behavior and then perhaps sustain more severe injuries that required an emergency department visit and subsequent hospitalization [24]. In the present study, high-energy falls were less common among the elderly than in the adult population. The majority of the elderly sustained a ground-level fall was supposed to occur upon walking or with movement, and more adult patients sustained a nonground-level fall occurring with more rigorous activity. This observation may contribute to the discrepancy in the proportion of patients and fatality rates according to gender among elderly and adult patients in fall accidents. Variations in lifestyle habits between people in different regions may also affect the different patterns of trauma in a fall [25]. However, our registered data were unable to provide more detailed information regarding the activity that induced the fall in the current study.

The factors affecting mortality in falls are very complex [27]. The mortality rates associated with falls from 3-6 m, 6-10 m, and >10 m were found to be increased 5 , 6.5, and 13 times, respectively, in comparison with the mortality rates of falls from $3 \mathrm{~m}$ or less [27]. In the present study, although more adult than elderly patients fell from a height between 1-6 $\mathrm{m}$ and $>6 \mathrm{~m}$, the mortality rates associated with falls were higher in the elderly than the younger population. (3.2\% vs. $1.3 \%$, respectively, $\mathrm{p}<0.001)$. Beside the age of the patient and the height of the fall, suicide attempt, type of ground on which the patient fell, place of fall, and head, thoracic, and abdominal trauma are the primary factors affecting mortality [27]. In addition, associated predisposing comorbidity is another factor that may influence the outcome in fall accidents. This current study revealed that these patients don't do worse because they are older, they do worse because they are chronically sicker. Brain injuries and injuries to the lower extremity are the most fatal of fall injuries in the elderly, accounting for $78 \%$ of fatalities and $79 \%$ of fallrelated costs [28]. Deaths due to falls result from multiple blunt traumas, especially head trauma [29]. In a postmortem study of 484 patients who had fallen or jumped from a height, the most frequently affected body part was the head (91\%) [30], followed by the thorax (54\%), abdomen (37\%), extremities (36\%), and neck (17\%). Falls are the most common cause of traumatic brain injury in the elderly and account for $46 \%$ of all fall-related deaths $[1,31]$. Among the pathologies related to head trauma, subdural hematoma was found to account for half of the mortality cases [32]. In the present study, the mortality of the elderly with subdural hematoma was found to be $18.2 \%$ (44/242), and, of the 78 fatal cases among the elderly patients, there were $44(56 \%)$ fatal cases of subdural hematoma. Notably, this study revealed that TRISS, a combination index developed by the Major Trauma Outcome Study (MTOS) performed in 1982 [33] based on revised trauma score (RTS), ISS, and patient's age to predict the mortality of injured patients, was not 
adequate to estimate the fatality rate among the elderly in fall accidents. TRISS appears to be valid for both adult and pediatric trauma cases [34]; however, because TRISS does not take into account pre-existing medical conditions [34], its application to elderly patients in fall accidents should be validated and a modified version of TRISS may need to be developed for better prediction of survival in elderly patients sustaining fall accidents.

As shown in this study, falls are the leading cause of nonfatal injury in the elderly population $[35,36]$. It had been reported that fractures occur in $3-12 \%$ of falls in the elderly and that hip fractures occur in less than $1 \%$ of all falls [37,38]; however, $90 \%$ of all hip fractures in the elderly are caused by a fall [39]. Occurring in $33 \%$ of nonfatal falls, fractures are the most common and costly fall injuries, and account for $61 \%$ of nonfatal fall-related costs [28]. In the first year following a femur fracture, $25 \%$ of elderly patients will die [40], $50 \%$ will experience a decline in performance of activities of daily living (ADLs) [40], and 76\% will experience a decline in their motility [1]. In the present study, a remarkably higher percentage of elderly patients suffered femoral fracture compared to the adult patients $(50.6 \%$ vs. $14.1 \%$, respectively, $\mathrm{p}<0.001$ ), and hip fracture, a femoral fracture that occurs in the proximal end of the femur, comprised $96.5 \%$ of femoral fracture in the elderly patients in fall accidents. In addition, the majority of elderly patients with a femoral fracture did not undergo surgery. The reasons, yet unidentified, may be attributed to a different injury pattern or conservative altitude of surgeons to perform operation in the elderly. In Taiwan, hip fracture rates are among the highest in the world, and the agespecific incidence rates of hip fractures have been found to increase with increasing age in both genders, in an exponential manner after 65 years of age [41]. The overall incidence of hip fractures showed a significant 30\% increase ( $\mathrm{p}<0.0001$ ) from 1996 to 2002, from 49.56 to 64.37 per 10,000 per year [42]. Notably, however, from 1999 to 2010, there was a decline in hip fracture rates among elderly Taiwanese adults with a concomitant increase in anti-osteoporosis medication expenditure [43]. Therefore, development and implementation of public health strategies for fall prevention should focus more on this geriatric group in Taiwan's rapidly aging society.

Our findings must be considered with some cautions. The limitations of this study include the use of a retrospective design and the lack of availability of data regarding the reasons, the risk factors, and circumstances of the mechanism of injury. Additionally, our single center study may not be representative of the entire population of Taiwan and our results may therefore not be generalizable. It is also possible that some of our patients suffered during the study period from recurrent falls that did not require emergency department visits and subsequent admissions, or following which these patients were treated elsewhere. In addition, the impact of pre-existing comorbidities in the elderly on the hospitalization course and on the mortality remains unclarified.

\section{Conclusion}

Elderly patients in fall accidents tend to experience a higher injury severity, a worse outcome, and a higher mortality rate compared to adult patients, as well as a bodily injury pattern differing from that of adults, indicating the need to emphasize fall prevention to reduce both the rate of falls and the associated injuries.

\section{Competing interests}

The authors declare that they have no competing interests.

\section{Authors' contributions}

CSR wrote the manuscript, TSL and SCW revised the manuscript, JCY, SYH and TYC carried out the analysis and edited the tables, $\mathrm{CHH}$ designed the study, contributed to the analysis and interpretation of data, and drafted the manuscript. All authors read and approved the final manuscript.

\section{Funding}

This research was supported by a grant from CDRPG8C0031.

\section{Author details}

${ }^{1}$ Department of Neurourgery, Kaohsiung Chang Gung Memorial Hospital and Chang Gung University College of Medicine, Kaohsiung City, Taiwan.

${ }^{2}$ Department of Trauma Surgery, Kaohsiung Chang Gung Memorial Hospital and Chang Gung University College of Medicine, No.123, Ta-Pei Road, Niao-Song District, Kaohsiung City 833, Taiwan. ${ }^{3}$ Department of Anesthesiology, Kaohsiung Chang Gung Memorial Hospital and Chang Gung University College of Medicine, Kaohsiung City, Taiwan. ${ }^{4}$ Department of Plastic and Reconstructive Surgery, Kaohsiung Chang Gung Memorial Hospital and Chang Gung University College of Medicine, Kaohsiung City, Taiwan.

Received: 4 August 2014 Accepted: 19 October 2014

Published online: 12 November 2014

\section{References}

1. Ambrose AF, Paul G, Hausdorff JM: Risk factors for falls among older adults: a review of the literature. Maturitas 2013, 75(1):51-61.

2. Rosen T, Mack KA, Noonan RK: Slipping and tripping: fall injuries in adults associated with rugs and carpets. J Inj Violence Res 2013, 5(1):61-69.

3. Hester AL, Wei F: Falls in the community: state of the science. Clin Interv Aging 2013, 8:675-679.

4. Hausdorff JM, Rios DA, Edelberg HK: Gait variability and fall risk in community-living older adults: a 1-year prospective study. Arch Phys Med Rehabil 2001, 82(8):1050-1056.

5. Inouye SK, Brown CJ, Tinetti ME: Medicare nonpayment, hospital falls, and unintended consequences. N Engl J Med 2009, 360(23):2390-2393.

6. Meschial WC, Soares DF, Oliveira NL, Nespollo AM, Silva WA, Santil FL: Elderly victims of falls seen by prehospital care: gender differences. Rev Bras Epidemiol 2014, 17(1):3-16.

7. Wendelboe AM, Landen MG: Increased fall-related mortality rates in New Mexico, 1999-2005. Public Health Rep (Washington, DC: 1974) 2011, 126(6):861-867.

8. Rockett IR, Regier MD, Kapusta ND, Coben JH, Miller TR, Hanzlick RL, Todd $\mathrm{KH}$, Sattin RW, Kennedy LW, Kleinig J, Smith GS: Leading causes of unintentional and intentional injury mortality: United States, 2000-2009. Am J Public Health 2012, 102(11):e84-e92.

9. Hartholt KA, Polinder S, van Beeck EF, van der Velde N, van Lieshout EM, Patka P, van der Cammen TJ: End of the spectacular decrease in fall-related mortality rate: men are catching up. Am J Public Health 2012, 102(Suppl 2):S207-S211.

10. Bergeron E, Clement J, Lavoie A, Ratte S, Bamvita JM, Aumont F, Clas D: A simple fall in the elderly: not so simple. J Trauma 2006, 60(2):268-273. 
11. Labib N, Nouh T, Winocour S, Deckelbaum D, Banici L, Fata P, Razek T, Khwaja K: Severely injured geriatric population: morbidity, mortality, and risk factors. J Trauma 2011, 71(6):1908-1914.

12. Pandya SR, Yelon JA, Sullivan TS, Risucci DA: Geriatric motor vehicle collision survival: the role of institutional trauma volume. J Trauma 2011 70(6):1326-1330.

13. Caterino JM, Valasek T, Werman HA: Identification of an age cutoff for increased mortality in patients with elderly trauma. Am J Emerg Med 2010, 28(2):151-158

14. Min L, Ubhayakar N, Saliba D, Kelley-Quon L, Morley E, Hiatt J, Cryer H, Tillou $A$ : The vulnerable elders survey- 13 predicts hospital complications and mortality in older adults with traumatic injury: a pilot study. J Am Geriatr Soc 2011, 59(8):1471-1476.

15. Taylor MD, Tracy JK, Meyer W, Pasquale M, Napolitano LM: Trauma in the elderly: intensive care unit resource use and outcome. J Trauma 2002, 53(3):407-414

16. AMA: Rating the severity of tissue damage: I. The abbreviated scale. JAMA 1971, 215(2):277-280

17. Baker SP, O'Neill B, Haddon W Jr, Long WB: The injury severity score: a method for describing patients with multiple injuries and evaluating emergency care. J Trauma 1974, 14(3):187-196.

18. Osler T, Baker SP, Long W: A modification of the injury severity score that both improves accuracy and simplifies scoring. J Trauma 1997, 43(6):922-925. discussion 925-926.

19. Boyd CR, Tolson MA, Copes WS: Evaluating trauma care: the TRISS method: Trauma Score and the Injury Severity Score. J Trauma 1987, 27(4):370-378

20. Champion HR, Sacco WJ, Copes WS, Gann DS, Gennarelli TA, Flanagan ME: A revision of the trauma score. J Trauma 1989, 29(5):623-629.

21. Hartholt KA, Polinder S, Van der Cammen TJ, Panneman MJ, Van der Velde N, Van Lieshout EM, Patka P, Van Beeck EF: Costs of falls in an ageing population: a nationwide study from the Netherlands (2007-2009). Injury 2012, 43(7):1199-1203

22. Mathers $L J$, Weiss HB: Incidence and characteristics of fall-related emergency department visits. Acad Emerg Med 1998, 5(11):1064-1070.

23. Hornbrook MC, Stevens VJ, Wingfield DJ, Hollis JF, Greenlick MR, Ory MG: Preventing falls among community-dwelling older persons: results from a randomized trial. Gerontologist 1994, 34(1):16-23.

24. Gelbard R, Inaba K, Okoye OT, Morrell M, Saadi Z, Lam L, Talving P, Demetriades D: Falls in the elderly: a modern look at an old problem. Am J Surg 2014, 208(2):249-253.

25. Kara H, Bayir A, Ak A, Akinci M, Tufekci N, Degirmenci S, Azap M: Trauma in elderly patients evaluated in a hospital emergency department in Konya, Turkey: a retrospective study. Clin Interv Aging 2014, 9:17-21.

26. Korhonen N, Kannus P, Niemi S, Palvanen M, Parkkari J: Fall-induced deaths among older adults: nationwide statistics in Finland between 1971 and 2009 and prediction for the future. Injury 2013, 44(6):867-871.

27. Icer M, Guloglu C, Orak M, Ustundag M: Factors affecting mortality caused by falls from height. Ulus Travma Acil Cerrahi Derg 2013, 19(6):529-535.

28. Stevens JA, Corso PS, Finkelstein EA, Miller TR: The costs of fatal and non-fatal falls among older adults. Inj Prev 2006, 12(5):290-295.

29. Turk EE, Tsokos M: Blunt cardiac trauma caused by fatal falls from height: an autopsy-based assessment of the injury pattern. J Trauma 2004, 57(2):301-304.

30. Goren S, Subasi M, Tyrasci Y, Gurkan F: Fatal falls from heights in and around Diyarbakir, Turkey. Forensic Sci Int 2003, 137(1):37-40.

31. Harvey LA, Close JC: Traumatic brain injury in older adults: characteristics, causes and consequences. Injury 2012,43(11):1821-1826.

32. Chisholm KM, Harruff RC: Elderly deaths due to ground-level falls. Am Forensic Med Pathol 2010, 31(4):350-354.

33. Champion HR, Copes WS, Sacco WJ, Lawnick MM, Keast SL, Bain LW Jr, Flanagan ME, Frey CF: The Major Trauma Outcome Study: establishing national norms for trauma care. J Trauma 1990, 30(11):1356-1365.

34. Chawda MN, Hildebrand F, Pape HC, Giannoudis PV: Predicting outcome after multiple trauma: which scoring system? Injury 2004, 35(4):347-358.

35. Sleet DA, Moffett DB, Stevens J: CDC's research portfolio in older adult fall prevention: a review of progress, 1985-2005, and future research directions. J Safety Res 2008, 39(3):259-267.

36. Peel NM: Epidemiology of falls in older age. Can J Aging 2011, 30(1):7-19.
37. Tinetti ME, Doucette J, Claus E, Marottoli R: Risk factors for serious injury during falls by older persons in the community. J Am Geriatr Soc 1995 43(11):1214-1221.

38. Tinetti ME, Speechley M, Ginter SF: Risk factors for falls among elderly persons living in the community. N Engl J Med 1988, 319(26):1701-1707.

39. Goldacre MJ, Roberts SE, Yeates D: Mortality after admission to hospital with fractured neck of femur: database study. BMJ (Clinical Research Ed.) 2002, 325(7369):868-869.

40. Abdelhafiz $\mathrm{AH}$, Austin $\mathrm{CA}$ : Visual factors should be assessed in older people presenting with falls or hip fracture. Age Ageing 2003, 32(1):26-30.

41. Chie WC, Yang RS, Liu JP, Tsai KS: High incidence rate of hip fracture in Taiwan: estimated from a nationwide health insurance database. Osteoporos Int 2004, 15(12):998-1002.

42. Shao CJ, Hsieh YH, Tsai CH, Lai KA: A nationwide seven-year trend of hip fractures in the elderly population of Taiwan. Bone 2009, 44(1):125-129.

43. Chan DC, Lee YS, Wu YJ, Tsou HH, Chen CT, Hwang JS, Tsai KS, Yang RS: A 12-year ecological study of hip fracture rates among older Taiwanese adults. Calcif Tissue Int 2013, 93(5):397-404.

doi:10.1186/s13049-014-0063-1

Cite this article as: Rau et al:: Geriatric hospitalizations in fall-related injuries. Scandinavian Journal of Trauma, Resuscitation and Emergency Medicine 2014 22:63.

\section{Submit your next manuscript to BioMed Central and take full advantage of:}

- Convenient online submission

- Thorough peer review

- No space constraints or color figure charges

- Immediate publication on acceptance

- Inclusion in PubMed, CAS, Scopus and Google Scholar

- Research which is freely available for redistribution 